Supporting Information

\title{
Ag Microplasma-Engineered Nanoassemblies on Cellulose Papers for Surface-Enhanced Raman Scattering and Catalytic Nitrophenol Reduction
}

Yi-Jui Yeh and Wei-Hung Chiang

Department of Chemical Engineering, National Taiwan University of Science \& Technology, Taipei 106, Taiwan

*Corresponding author e-mail: whchiang@mail.ntust.edu.tw 


\section{S1. SEM and electrical sheet resistance measurement}

To study the uniformity and size of the area treated by plasma, we have provided the SEM images and four-point probe electrical resistance measurement of 10 different locations (Fig. S2 (b)) of one typical plasma-treated sample. The sample is with the area of $5 \mathrm{~cm}$ by $1 \mathrm{~cm}$ (Fig. S2 (a)). Fig. S2 (c) shows a series of SEM images of 10 difference locations of one sample. The SEM images indicate uniform coatings of Ag nanoparticles at the locations closed to the center, the area of location 2, 3, 4, 6, 7, 8, and 9 shown in Fig. S2 (b). However, less uniform coatings of Ag nanoparticles were exhibited at the edge areas of location 1 and 10 shown in Fig. S2 (b). Moreover, the thin film-based sheet resistance measurement using a commercial fourpoint probe indicates the very similar sheet resistances about $\sim 10^{-4} \Omega /$ square for center areas while much higher resistances about $\sim 10^{-1} \Omega /$ square was detected for edge areas. The above results suggest the plasma treatment can creative uniform coating of $\mathrm{Ag}$ nanoparticles on papers with area about $4 \mathrm{~cm}$ by $1 \mathrm{~cm}$ in our experimental setup.

\section{S2. Enhanced factor calculation}

To estimate the EF from cellulose paper based substrates, it is reported to use the ratio of (ISERS/CSERS $) /\left(I_{R} / C_{R}\right)$. The $C_{S E R S}$ is the concentration of R6G solution on the SERS substrates and $C_{R}$ is the concentration of $\mathrm{R} 6 \mathrm{G}$ solution $\left(10^{-4} \mathrm{M}\right)$ that produces a spontaneous Raman signal on bare papers. In addition, $I_{\text {SERS }}$ and $I_{R}$ denote the integrated Raman intensities of R6G under the above experimental conditions. The calculation is provided in the following:

$\mathrm{EF}=\left(I_{S E R S} / C_{S E R S}\right) /\left(I_{R} / C_{R}\right)=\left(6.13 / 10^{-12} M\right) /\left(5.84 / 10^{-4} M\right) \sim=1.05^{*} 10^{8}$. 


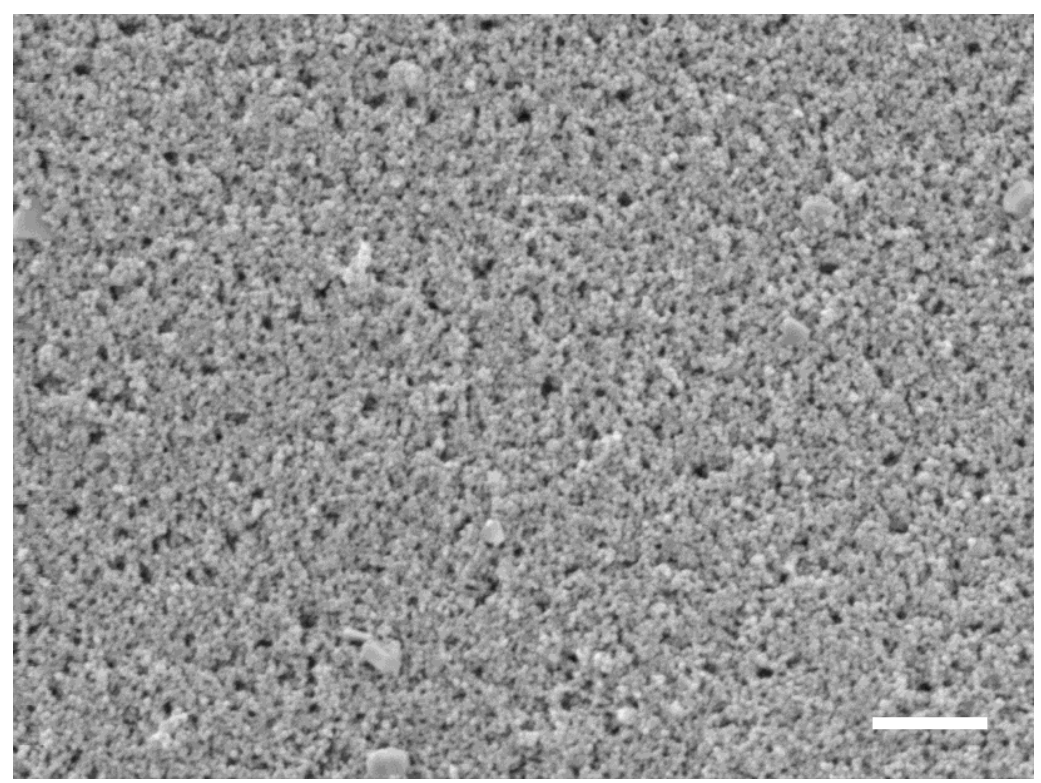

Figure S1. Representative SEM image of the as-fabricated sample dried in oven with $50{ }^{\circ} \mathrm{C}$ for 30 minutes. Scale bar: $500 \mathrm{~nm}$. 
(a)

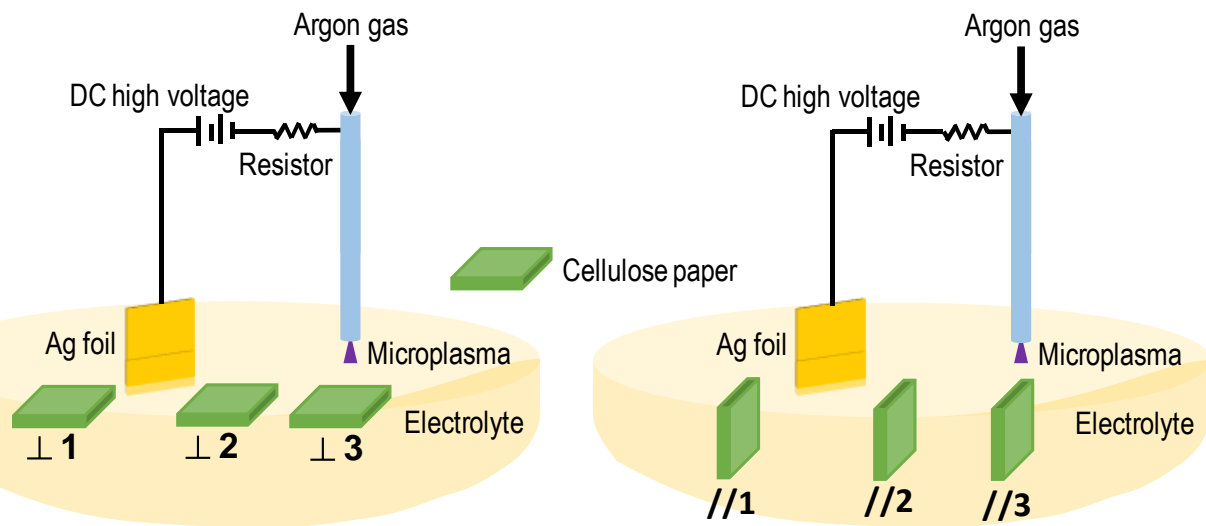

(b)

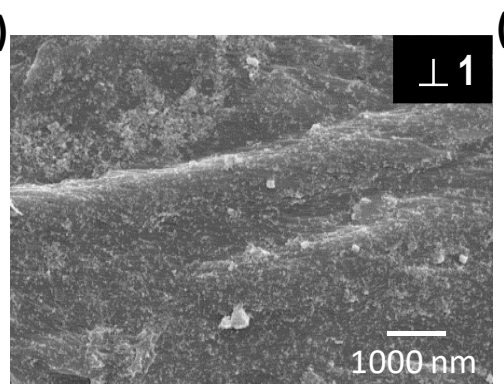

(e)

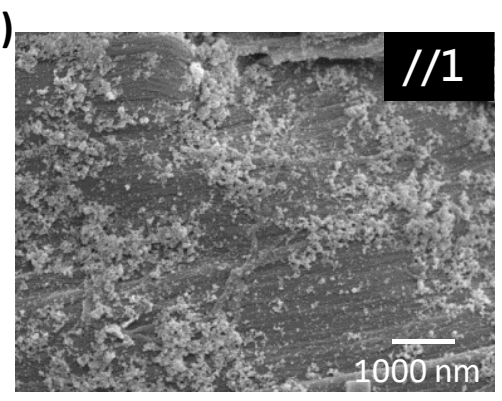

(c)

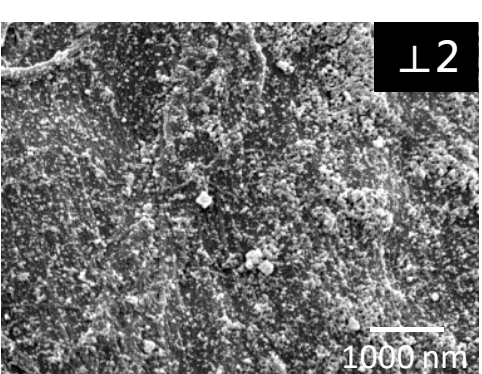

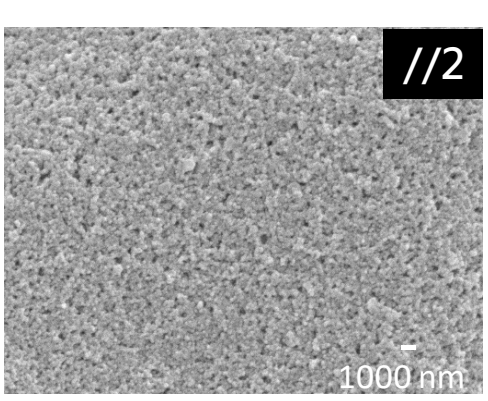

(g)
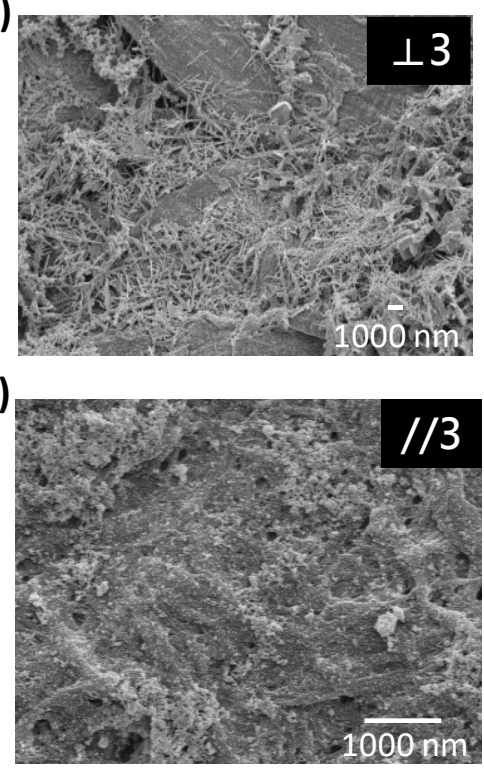

Figure S2. (a) Schematic illustration of fabrications of AgMENs with different configurations and locations in the plasma reactor. $\perp$ and // denote the configurations of vertical and parallel to the plasmas. 1, 2, and 3 denote the locations of anode side, in between anode and cathode, and cathode side. (b) to (g) SEM images of the as-fabricated AgMENs prepared with different configurations and locations in the plasma reactor. 
(a)

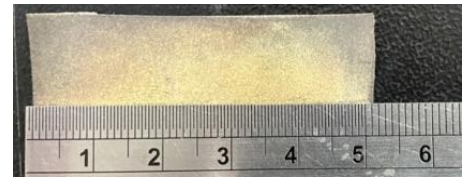

(b)

\begin{tabular}{|l|l|l|l|l|}
\hline 1 & 2 & 3 & 4 & 5 \\
\hline 6 & 7 & 8 & 9 & 10 \\
\hline
\end{tabular}
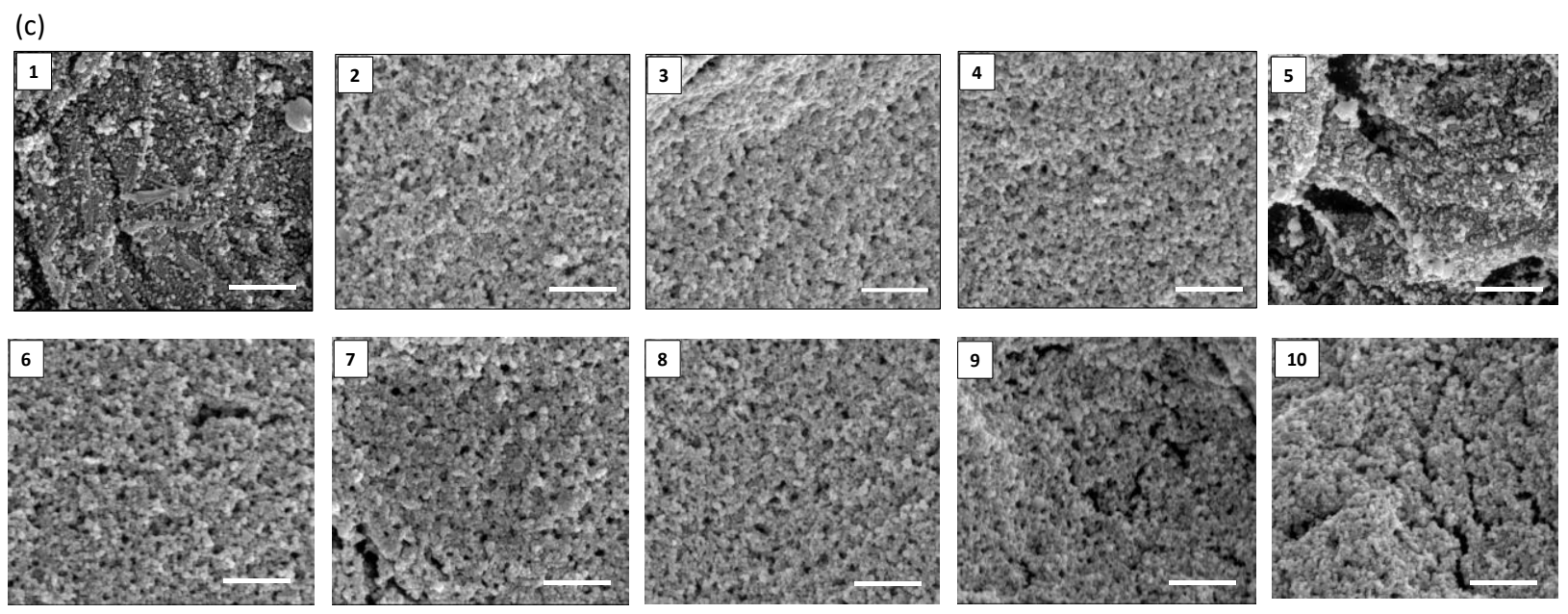

Figure S3. (a) A typical plasma-treated sample. (b) the 10 locations for SEM observation and electrical measurement. (c) The 10 SEM images observed from the 10 corresponding locations shown in (b). Scale bar: $500 \mathrm{~nm}$. 
(a)

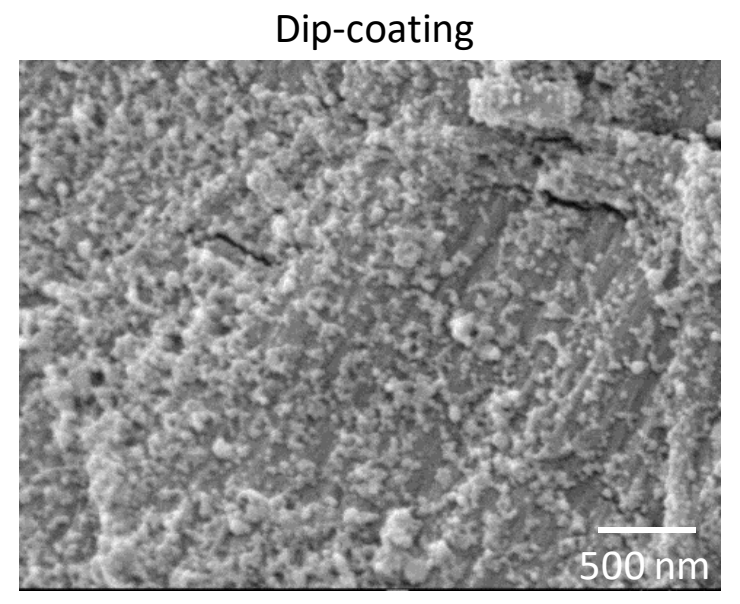

(b)

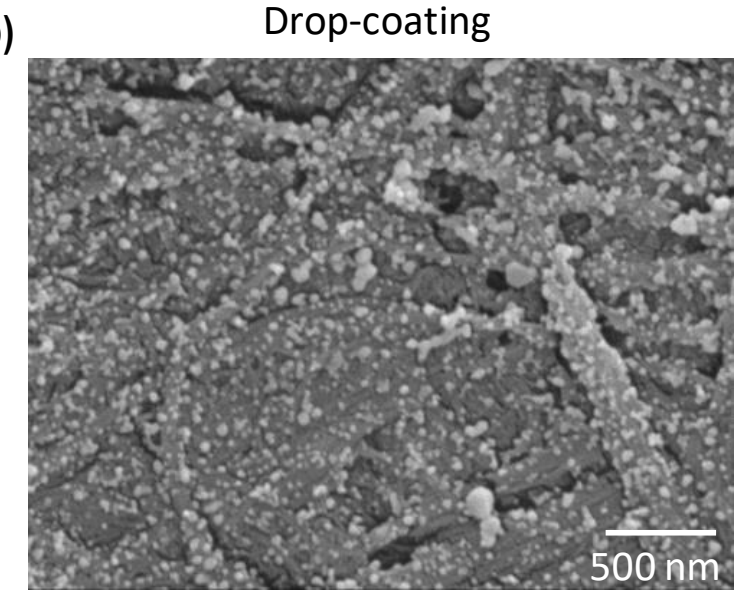

Figure S4. SEM images of coatings of Ag NPs on cellulose papers using (a) dip coating and (b) drop coating methods. 


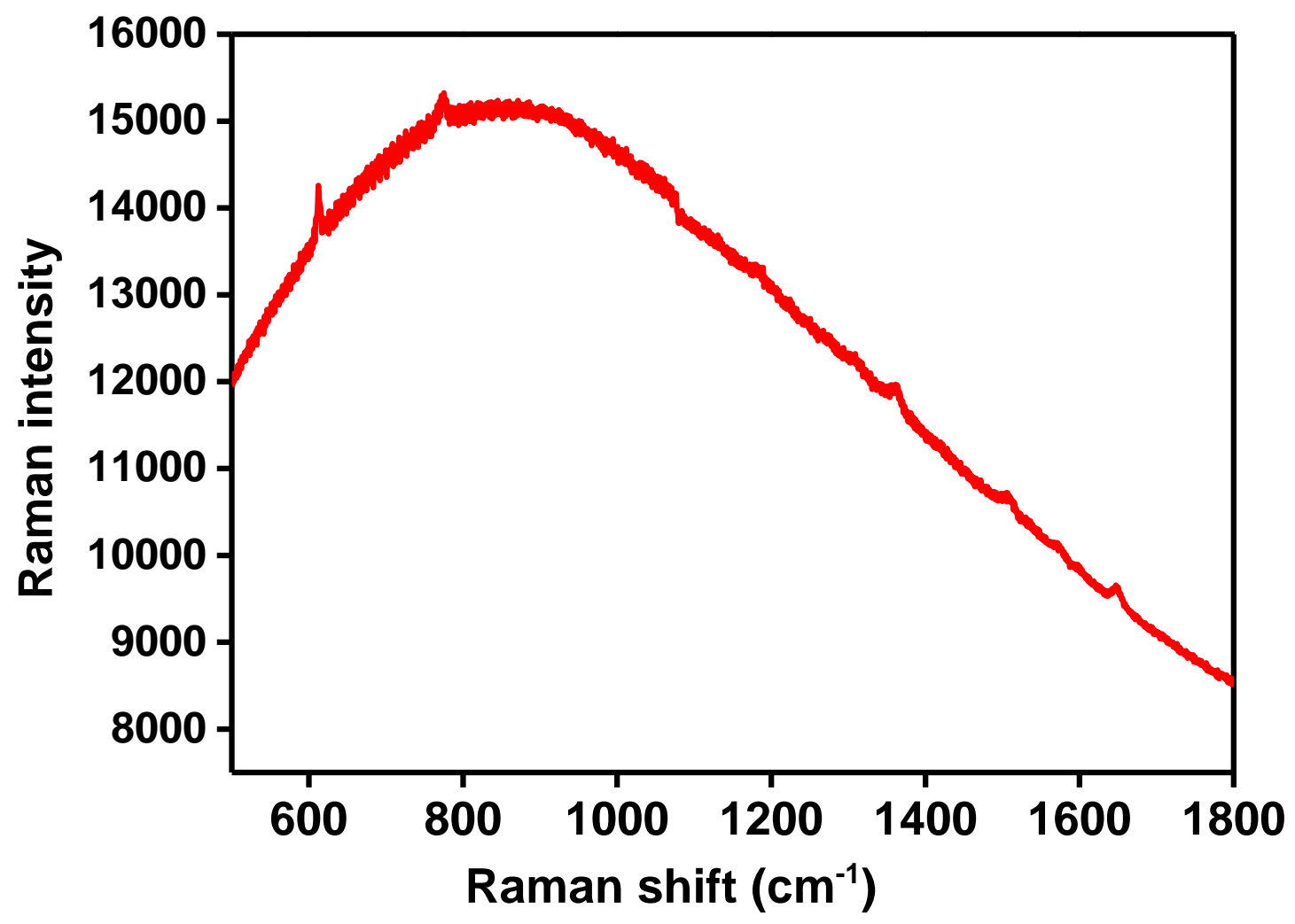

Figure S5. Raman spectrum of the filter paper for $10^{-3} \mathrm{M}$ R6G. 


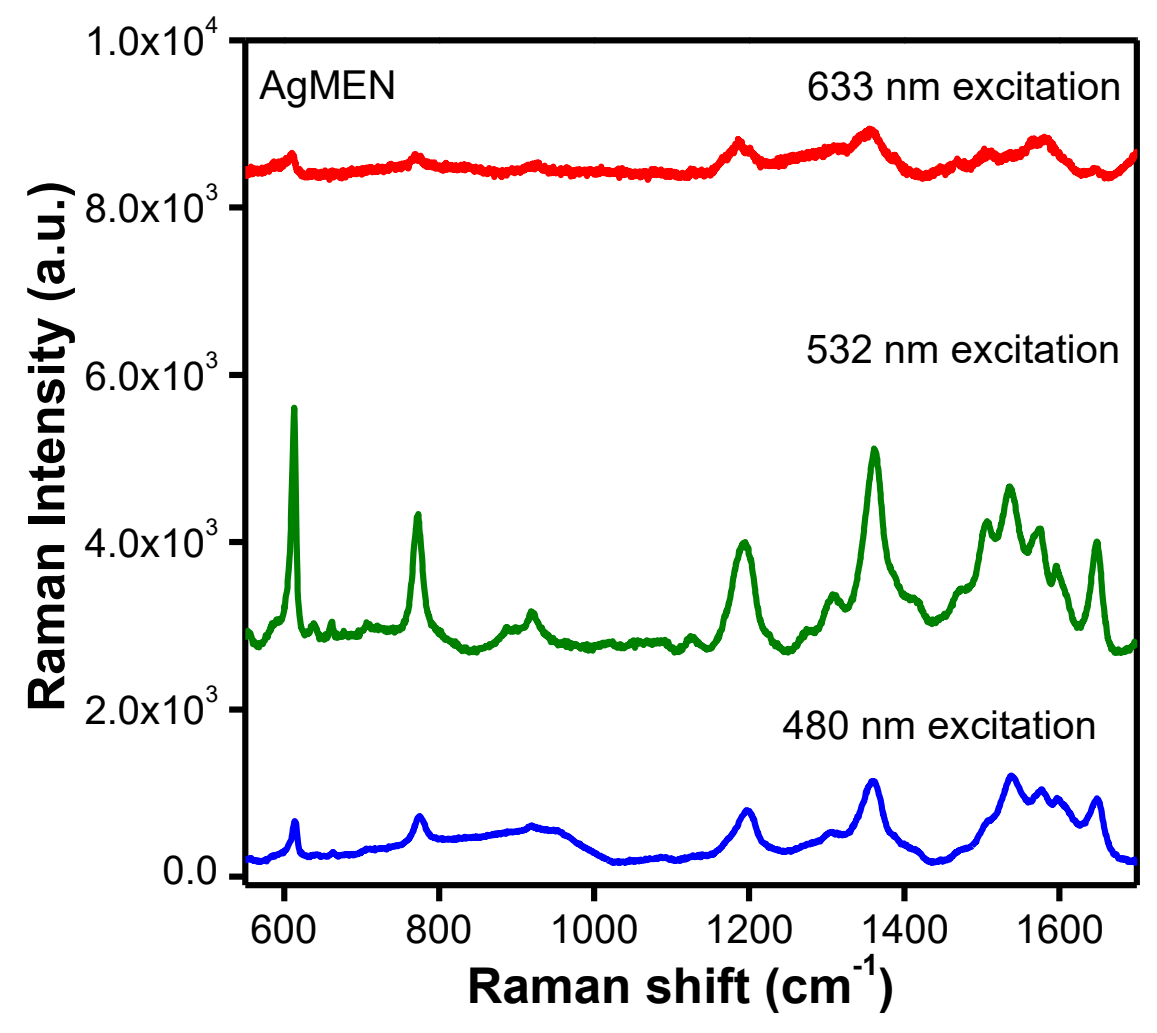

Figure S6. Raman spectra of $10^{-4} \mathrm{M}$ R6G on fabriacted AgMEN with different laser excitations. 
(a)

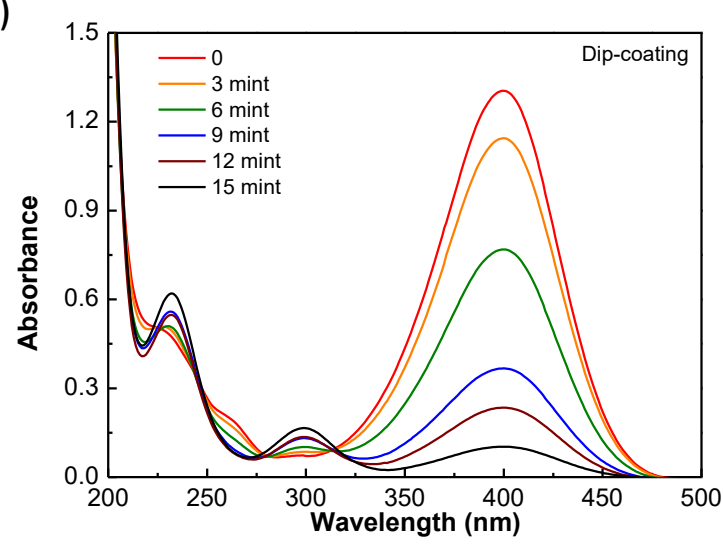

(b)

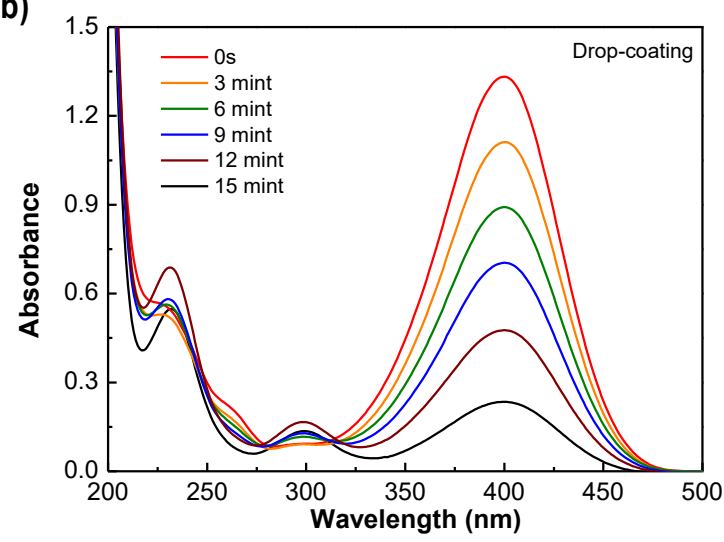

Figure S7. UV-Vis absorption spectra for the 4-NP degradations with (a) dip-coating and (b) dropcoating Ag catalysts. 
Table S1. The summarized table of electrical resistances measured from the 10 corresponding locations shown in Figure S2(b).

\begin{tabular}{cccccc}
\hline Location & $\mathbf{1}$ & $\mathbf{2}$ & $\mathbf{3}$ & $\mathbf{4}$ & $\mathbf{5}$ \\
Sheet resistance $(\Omega /$ square $)$ & $3.12 \times 10^{-1}$ & $4.89 \times 10^{-4}$ & $7.53 \times 10^{-4}$ & $5.17 \times 10^{-4}$ & $4.13 \times 10^{-1}$ \\
\hline Location & $\mathbf{6}$ & $\mathbf{7}$ & $\mathbf{8}$ & $\mathbf{9}$ & $\mathbf{1 0}$ \\
Sheet resistance $(\Omega /$ square $)$ & $2.25 \times 10^{-4}$ & $5.57 \times 10^{-4}$ & $7.81 \times 10^{-4}$ & $6.93 \times 10^{-4}$ & $4.79 \times 10^{-4}$ \\
\hline
\end{tabular}


Table S2. Characteristic frequencies and assignments of IR vibration bonds.

\begin{tabular}{ccc}
\hline Peak & Frequency $\left(\mathrm{cm}^{-1}\right)$ & Assignment \\
\hline A & 3391 & $-\mathrm{OH}$ stretching \\
B & 2906 & $-\mathrm{CH}$ stretching \\
$*$ & 1627 & OH of water absorbed from cellulose \\
C & 1427 & CH2 symmetric bending \\
D & 1167 & C-O-C asymmetric stretching \\
E & 1108 & Ring asymmetric stretching \\
F & 1035 & C-O stretching \\
G & 897 & CH bending \\
\hline
\end{tabular}


Table S3. Process times and NP densities of different samples, and reaction rate constants $(\mathrm{k})$ at $25{ }^{\circ} \mathrm{C}$ and estimated activation energies (E) of different samples for 4-NP reduction.

\begin{tabular}{ccccc}
\hline Sample & $\begin{array}{c}\text { Process time } \\
(\mathrm{min})\end{array}$ & $\begin{array}{c}\text { NP density } \\
\left(\# / \mu \mathrm{m}^{2}\right)\end{array}$ & $\begin{array}{c}\mathrm{k}_{\text {app }} \\
\left(\mathrm{min}^{-1}\right)\end{array}$ & $\begin{array}{c}\mathrm{E}_{\mathrm{a}} \\
(\mathrm{kJ} / \mathrm{mol})\end{array}$ \\
\hline AgMEN & 20 & $2059 \pm 132$ & 1.13 & 4.6 \\
Dip-coating & 4340 & $875 \pm 129$ & 0.16 & 31.3 \\
Drop-coating & 45 & $568 \pm 68$ & 0.10 & 38.5 \\
\hline
\end{tabular}

